\title{
Nucleic Acids
}

National Cancer Institute

\section{Source}

National Cancer Institute. Nucleic Acids. NCI Thesaurus. Code C706.

Type of substance that may be described as a linear sequence of nucleosides typically linked through phosphate esters. 